\title{
Correction to: Coumarins as Potential Antiprotozoal Agents: Biological Activities and Mechanism of Action
}

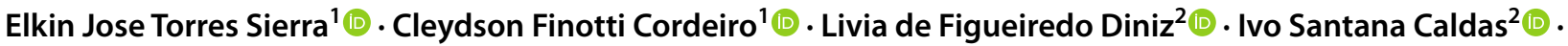 \\ Jamie Anthony Hawkes ${ }^{1}\left[\right.$. Diogo Teixeira Carvalho ${ }^{1}$ [
}

Published online: 18 October 2021

(C) The Author(s) under exclusive licence to Sociedade Brasileira de Farmacognosia 2021

\section{Correction to: Revista Brasileira de Farmacognosia (2021) https://doi.org/10.1007/s43450-021-00169-y}

This article has been corrected and the funding information will appear as:

Funding This study was financially supported by the Universidade Federal de Alfenas under the "PIB-Pós Scholarship" and was also financed in part by the Coordenação de Aperfeiçoamento de Pessoal de Nível Superior-Brazil (CAPES)_Finance Code 001 and by the "Fundação de Amparo à Pesquisa do Estado de Minas Gerais (FAPEMIG)", under Process Number APQ-00686-18. The authors wish to acknowledge and thank both parties for their financial support.

The original article has been corrected.

The original article can be found online at https://doi.org/10.1007/ s43450-021-00169-y.

\footnotetext{
Diogo Teixeira Carvalho

diogo.carvalho@unifal-mg.edu.br

1 Faculdade de Ciências Farmacêuticas, Universidade Federal de Alfenas, Rua Gabriel Monteiro da Silva 700, Alfenas, Minas Gerais 37130-001, Brazil

2 Instituto de Ciências Biomédicas, Universidade Federal de Alfenas, Rua Gabriel Monteiro da Silva 700, Alfenas, Minas Gerais 37130-001, Brazil
} 